\title{
ERBB2 Mutation Analysis Was Performed
}

National Cancer Institute

\section{Source}

National Cancer Institute. ERBB2 Mutation Analysis Was Performed. NCI Thesaurus.

Code C160357.

An indication that ERBB2 mutation analysis was performed during the study. 